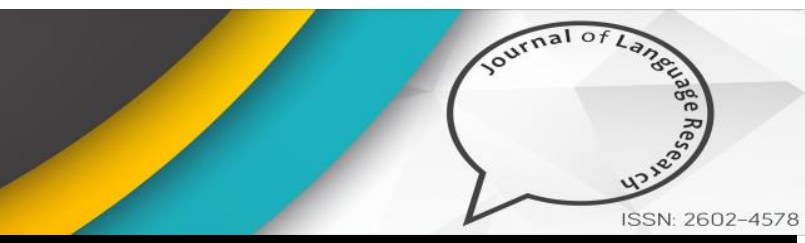

Research Article

\title{
The Role of Pedagogical Translation on The Development of Intercultural Communicative Competence in Language Teaching
}

\author{
Esra Başak Aydınalp ${ }^{1}$,Erzincan Binali Yıldırım Üniversitesi, French Language Teaching, \\ ebaydinalp@erzincan.edu.tr
}

Recommended citation: Aydınalp, E. B. (2020). The Role of Pedagogical Translation on The Development of Intercultural Communicative Competence in Language Teaching. Journal of Language Research (JLR), $4(1), 69-85$.

\begin{abstract}
Methods of language teaching, up to the boost of communicative approach, have neglected the role of pedagogical translation throughout the twentieth century in order to prevent the use of the L1 (the mother tongue) in the classroom. With the elaboration of Common European Framework of Reference for Languages (CEFR) in 2001, there has been a radical shift from an interactional language learning perspective at a bilingual environment to an intercultural perspective at a multilingual level with the recent theories of sociocultural learning and the emergence of intercultural competence. This study intends to redraw the theoretical background of translation in language learning after the traditional grammar-translation method and to deconstruct the neglected role of translation in the emerging methods during the second half of the twentieth century up to communicative and action-oriented approaches. The study aims at reinitiating the translation-based learning in coherence with the action-oriented approach, which is based upon the appropriation of an Intercultural Communicative Competence in language teaching. It was a qualitative phenomenographic research and the researcher examined data collected from ten experts and three main categories had been determined. The main theme was the impact of translation on intercultural communicative competence, which was divided into three categories (role, impact, and awareness via translation) It has been concluded that the translation is a way to surpass cultural boundaries in language teaching and the role of translating is a kind of mediation. Translation is not only an activity of transcoding, but also a complex procedure in which interfere language, culture, but also the inter-subjective pragmatic relations between individuals and the society.

Keywords: Pedagogical translation, Intercultural Communicative Competence, Action-oriented approach, CEFR, Foreign Language Education
\end{abstract}

\section{INTRODUCTION}

"In order to translate a foreign language, one should fulfil two conditions which are both necessary and not enough on their own: to study the foreign language; and to study (systematically) ethnography of the community in which this translated language is expressed."

George Mounin

Under the increasing influence of globalization, demographic and immigration movements, the activities of translation become a widespread phenomenon in order to cope with multicultural and multilingual demands enhancing during the last decades in Europe and worldwide. These circumstances lead the European Community to elaborate a CEFR (2001) based upon the satisfaction of deeds of language learning and communication requirements in a multilingual environment that challenge the promotion of a social and intercultural competence in an action-based language-teaching curriculum. Traditional methods of language teaching have neglected the role of pedagogical translation throughout the twentieth century in order to prevent the use of the L1 in the classroom. Yet, with the arrival of action-oriented approach, we witness at a regain of interest of the use of translation

${ }^{1}$ ORCID: 0000-0001-8035-5917

Submitted: 04.08 .2020

Accepted: 08.12.2020 
in a foreign language class. In this study, we will examine the reasons of the ignorance announced above and deconstruct the negligence of translation in the emerging methods during the second half of the twentieth century up to communicative approach. The researcher intends to reinitiate the translation-based learning in coherence with the action-oriented approach, which is based also on the appropriation of an Intercultural Communicative Competence in language teaching (Byram\& Zarrate, 1996; Byram \& Flemming ; 1998, Byram, Nichols \& Stevens, 2001; Byram, Gribkova \&Starkey, 2002; Zarrate, 2003; M Byram, P Holmes \& N Savvides ,2013; Byram, 2012). Camphell (2002) claims that EFL (English as a foreign language) teaching methods often disapprove the use of the first language altogether and as a consequence ignore the potential of translation in language learning and he enumerates four factors that undermine the lack on integration of translation and EFL as 1) a strong anti-translation bias in EFL teaching methodology; 2) lack of recognition of translation in EFL publishing industry; 3) obstacles stemming from the demographics of EFL; 4) lack of interest from translation. Nevertheless, Naimushin (2002) claims that translation could be considered as the fifth skill alongside the other four in a foreign language class. The potential of translation activities to develop foreign language skills (Camphell, 2002; Elorza, 2008; Beaven \&Alvarez 2004; Kocbek, 2014 ) is mostly ignored by foreign language teachers. The researcher in this paper intends to undo the negligence of translation activities in foreign language teaching and to analyse the effects of translation studies as a strategy that could be used in SLA (Second Language Acquisition) as a key factor in order to apprehend the skills necessary in a learning directed to the achievement of an intercultural communicative competence which requires mutual understanding and awareness of not only the culture of the self but also the others.

\section{THEORETICAL FRAMEWORK}

"To speak a language is to take on a world, a culture."

Frantz Fanon

Translation as a method dates from the $16^{\text {th }}$ century while the teaching of Greek-Latin and vice-versa, and the reputation of the translation as a major method in order to teach a foreign language was during the $19^{\text {th }}$ century when it was used to understand and learn grammatical rules in target language. This method named originally as Grammar-Translation method was focused on learning grammar rules and vocabulary. Some researchers (Cook 2010, Malmkjaer 1998) determine actually the neglect of translation in SLA throughout the $20^{\text {th }}$ century and they associate this undermining to the GrammarTranslation method. Thus, this method privileged formal accuracy in writing and prevents the use of language as a communicative tool. It requires a word-to-word equivalence, which neglects the social and pragmatic aspects of the language in context. The Direct Method banned the use of translation to facilitate learning in foreign language classes by giving priority to oral interactions. Since the emergence of the Direct Method, the foreign language teaching put the emphasis on natural learning, which is a kind of immersion in the language just like a child do in his/her first contact with his mother tongue without grammar or translation. Translation, as a learning skill and strategy, has been under suspicion and effectively banned from the foreign language classroom. (Davies, 2012, p. 16). Until the arrival of the Communicative Approach and task-based teaching approaches, language teaching sees translation as a detriment activity, which prevents communication, yet Vermes (2010, p. 91) points out of the using of pedagogical translation as a strategy in SLA (Second Language Acquisition) as below:

"...translation is not only structure manipulation; it is primarily a form of communication. And as such, it necessarily involves interaction and cooperation between people, which makes it a potentially very useful device in FLT". 
Despite the progress in language teaching methods, the use of translation in second and foreign language classrooms is still been perceived as a threat to the effectiveness of a satisfied communication and interaction among the learners. However, in this paper we will discuss the usefulness of the translation as a pedagogic strategy, which aims at the enhancing of the effectiveness of the intercultural communicative competence.

"Because intercultural speakers/mediators need to be able to see how misunderstandings can arise, and how they might be able to resolve them, they need the attitudes of decentring but also the skills of comparing. By putting ideas, events, documents from two or more cultures side by side and seeing how each might look from the other perspective, intercultural speakers/mediators can see how people might misunderstand what is said or written or done by someone with a different social identity. The skills of comparison, of interpreting and relating, are therefore crucial: Skills of interpreting and relating (savoir-comprendre): ability to interpret a document or event from another culture, to explain it and relate it to documents or events from one's own" (Byram, 2000, p. 12)

Since the emergence of communicative approach in 1970s, there has been a reconsideration of the new ways the peoples of different cultures and languages react and the way of their communication influence the interaction among them. The cultural turn- the introduction of Intercultural Communicative Competence (ICC) to complement Communicative Competence -has further refined the notion of what is to be competent for communication with speakers of different languages and with speakers using a lingua franca. Teachers and learners now need to be aware of the other people's cultures as well as their own and therefore the term ICC has emerged along with other terms such as "cultural awareness" and "transnational competence".

According to Beneke, Intercultural Competence is to a large extent the ability to cope with one's own cultural background in interaction with others" (2000, p.109). In such an approach, the intercultural aspects of communication deal, in Kramsch's words, with 'the meeting between people from different cultures and languages across the political boundaries of nation-states' (Kramsch, 1998, p.128). According to Byram, a person having an intercultural communicative competence is able to recognise externally and internally the relationships between cultures among a given society and he/she has a critical and analytical interpretation on his/her own culture and the other cultures and is aware that his/her perspective is culturally determined rather than being natural. (2000, p. 10)

As Elorza (2008) states students mostly recourse to translation in cases of problem-solving activities and decision making about the translated text and determining various forms of sayings and cultural norms in order to evaluate perceptions from the target culture. Thus, the arrival of actionbased approach in foreign language teaching as designed in CEFR and the enhancing studies on bilingual perspectives, the recourse to develop Intercultural Communicative Competence in a multicultural and globalized world has become necessary. It is required not only for language learners and but also for teachers to envisage language as a tool of contact and of mediation in which the role of translation becomes more and more central.

With the elaboration of Common European Framework of Reference for Languages in 2001, there has been a radical shift from an interactional language learning perspective at a bilingual environment to a sociocultural and intercultural perspective at a multilingual level with the recent theories of sociocultural learning and the emergence of intercultural competence. As it is defined in the CEFR: 
The Role of Pedagogical Translation on The Development of Intercultural Communicative Competence in Language Teaching

"Users of the Framework may wish to consider and where appropriate state:

- what prior sociocultural experience and knowledge the learner is assumed/required to have;

- what new experience and knowledge of social life in his/her community as well as in the target community the learner will need to acquire in order to meet the requirements of L2 (second language) communication;

- what awareness of the relation between home and target cultures the learner will need so as to develop an appropriate intercultural competence." (CERF, 2001, p.103)

The shift announced above influenced the scope of translation activities to transfer both linguistic skills and cultural capacities whereas skill of analysis of a text became more important than mere information in order to cope with the cultural, social, psychological and anthropological aspects inherent to any translation activity. There has been a shift in the place of the translation in language learning which was firstly associated to a form of searching equivalences in a literal text towards a perspective of mediation between language and culture. Besides the concept of culture has changed over time from emphasis on literature, the arts and philosophy to culture as a shared way of life. (Byram, 2000, p.10) So according to Byram, ICC needs to develop the deeds such as:

"Attitudes: curiosity and openness, readiness to suspend disbelief about other cultures and belief about one's own. Knowledge: of social groups and their products and practices in one's own and in one's interlocutor's country, and of the general processes of societal and individual interaction.

Skills of interpreting and relating: ability to interpret a document or event from another culture, to explain it and relate it to documents from one's own.

Skills of discovery and interaction: ability to acquire new knowledge of a culture and cultural practices and the ability to operate knowledge, attitudes and skills under the constraints of real-time communication and interaction.

Critical cultural awareness/political education: an ability to evaluate critically and on the basis of explicit criteria perspectives, practices and products in one's own and other cultures and countries." (Byram, 2000, p.10)

Indeed, under the influence of the communicative approach promoted by English as a Second Language, Kramsch (2013) differentiates language pedagogy from literary pedagogy asserting that the former referring to culture as "small c" of daily life focusses on communicative competence and acquisition of conversational skills and the latter referring to culture as "big C" of literature and arts focusses on the analysis, interpretation and translation of texts from one language into another. Culture will be envisaged as "big C" in the concept of civilisation and will be called "small c" in the concept of beliefs and behaviours. (Halverson, 1985 cited by Lazar, Krieger and al, 2003).

The objective of language learning is defined in terms of the intercultural competence, which is "the ability of a person to behave adequately in a flexible manner when confronted with actions, attitudes and expectations of representatives of foreign cultures" (Meyer, 1991, p.138). This definition emphasizes not only the communicative competence but also incorporates the intercultural competence as a part of it.

Translation is mostly acknowledged as a medium to enhance metalinguistic awareness of differences between languages in university students (Anderson, 2018) or as a useful practice to 
improve written abilities in low-proficiency students (Woo Lee, 2018). It can also be interpreted as a mean to make inferences between two languages. Foreign language teaching especially ELT (English Language Teaching) focuses on oral dimension of language and has been favouring a specific emphasis on ICC (Intercultural Communicative Competence (Balboni, 2005; cited by Fois, 2020). To embed the ICC in translation process should help to overcome the opposition to translation in language teaching. (Fois, 2020, 562) Naimushin (2002) claims that translation could be considered as the fifth skill alongside the other four in a foreign language class. The potential of translation activities to develop foreign language skills (Camphell, 2002; Elorza, 2008; Beaven \&Alvarez 2004; Kocbek, 2014) is mostly ignored by foreign language teachers. Nevertheless translation-based learning should be an asset to contribute to develop the intercultural communicative competence (Byram\& Zarrate, 1996; Byram \& Flemming ; 1998, Byram, Nichols \& Stevens, 2001; Byram, Gribkova \&Starkey, 2002; Zarrate, 2003; M Byram, P Holmes \& N Savvides ,2013; Byram, 2012), which is a milieu to encounter the "other" and the "self".

Therefore, this study aims at responding the questions below:

1. What is the importance of pedagogical translation?

2. How could the pedagogical translation be used as a key factor in order to familiarize with the target language culture?

3. How can the pedagogical translation contribute to enhance the awareness of the culture of the self?

4. What is the contribution of translation-based learning in the development of Intercultural Communicative Competence?

Respectively, the researcher will analyse the effects of translation studies as a strategy that could be used in Second Language Acquisition as a key factor in order to apprehend the skills necessary in a learning directed to the achievement of an intercultural communicative competence which requires mutual understanding and awareness of not only the culture of the self but also the others.

\section{METHODOLOGY}

\section{Study design}

This study was conducted with a qualitative research method. Qualitative data with their emphasis on people lived experiences, are fundamentally well suited for locating the meanings people place on the events, processes and structure of their lives and for connecting theses meaning to the social world around them. (Miles, Huberman, 2014, p.11) The research design among qualitative research, which is suited best for this study, is therefore phenomenograpy. Phenomenography is a research method adapted for mapping the qualitatively different ways in which people experience, conceptualize, perceive, and understand various aspects of, and phenomena in, the world around them (Marton, 1986, p.31). Phenomenography was developed and practiced for some years before it was named and designated as a distinct research design. Its origins stem from the research on 'approaches to learning' (i.e. the different ways in which students conceive of and go about their learning) carried out at Goteborg University in Sweden in the 1970s by Marton, Svensson, Dahlgren, Saljo and others. (Tight, 2016). Thus, the researcher aim is to discern the perceptions and beliefs of foreign language teachers on language teaching about the place of translation in enhancing Intercultural Communicative Competence of students. 
The Role of Pedagogical Translation on The Development of Intercultural Communicative Competence in Language Teaching

\section{Participants}

The sample used in phenomenographic study is purposive. Purposeful sampling is mostly used in phenomenography with a special emphasis on qualitative researches. It ensures deeper understanding and information-rich cases in order to get crucial amount of relevant data to conduct properly the research (Patton, 2002, p.46). Participants in a phenomenographic study are determined according to their relevance to the purpose of the study and the experience of the participants of the phenomenon being explored. (Yates\&Bruce, 2012, p.103). Therefore, the research was conducted with ten academicians in three universities (seven participants from Anadolu University, one participant from Galatasaray University, two participants from Erzincan University) and from the departments of German, English and French Teaching as a second or foreign language.

Table 1. Participants' Features

\begin{tabular}{cccc}
\hline Participant & Age & Department & Experience /years \\
\hline P1 & 32 & English & 10 \\
P2 & 38 & French & 5 \\
P3 & 64 & French & 34 \\
P4 & 52 & German & 29 \\
P5 & 49 & French & 23 \\
P6 & 44 & German & 21 \\
P7 & 47 & French & 27 \\
P8 & 25 & French & 1 \\
P9 & 35 & French & 12 \\
P10 & 30 & German & 7 \\
\hline
\end{tabular}

\section{Ethical Concern}

The participants are previously all informed about the nature of the study by a research consent form on which they could find the questions to be replied. Their consent for the study was obtained via the Interview Consent Form. The names of the participants are altered in the study and pseudonyms are assigned instead of the names of the participants in the present study. Their pseudonyms are utilized when quoting the responses of participants.

\section{Data Collection}

The data was collected from the participants stated above via E-Mail du the fact that the researcher was not able to displace. There were seven open-ended questions and the questions were semi-structured. The responses were collected during November 2019. The participants were given a duration of fifteen days to reply the questions. Data is coded by the researcher and one of the colleagues from Foreign Language Teaching. The collected data is examined in order to scrutinize the impact of translation on ICC, three main themes emerged according to the saturation of themes which reappears during the analyse. So, the main theme was the impact of translation on intercultural communicative competence, which was divided into three categories (role, impact, and awareness via translation) and ten subcategories. 


\section{Reliability}

According to Miles and Huberman (1994, p.64) the data is coded at least by two intercoders in order to validate the results. Check-coding is a good reliability check procedure and ensure clarity. The eventual inter-code agreement should be up in the $\% 90$ range depending on the size and range of the coding scheme. Thus, in the current study the data is coded by more than one intercoder, the researcher and one colleague from the Foreign Language Teaching Department. The first intercoder defined 10 codes and the second intercoder defined 12 codes initially. The total number of initial codes was 22. The reliability is calculated using the formula as defined by Miles and Huberman (1994, p.64):

Number of agreements (22)

Reliability $=$ $\% 91$

Total Number of agreements (22) + Number of disagreements (2)

\section{Data Analysis}

The researcher examined and coded the collected data. According to Miles and Huberman (1994, p.58) one method of creating codes is that of creating provisional start list of codes prior to work. That list comes from the conceptual framework, list of research questions, hypotheses, problem areas and key variables that the researcher brings to study. So, in that research, the researcher created a list of codes according to research questions, hypotheses and key variables that has the potential to influence the study in question and she defined three main categories. The main theme was the impact of translation on intercultural communicative competence, which was divided into three categories (role, impact, and awareness via translation) and ten subcategories. These categories and themes are illustrated in Table 2 as follows:

Table 2. Main Themes and Subcategories

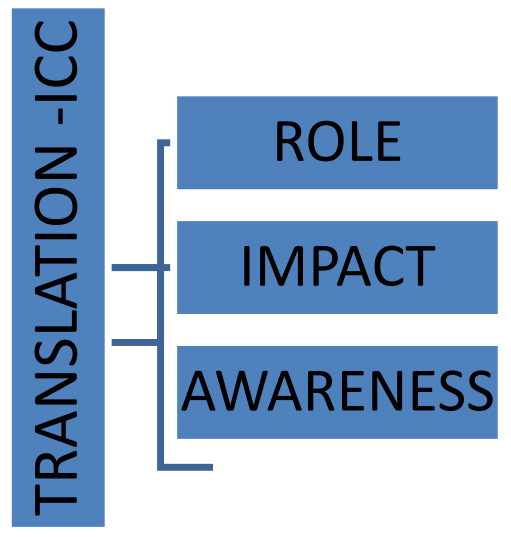




Role
- Recourse to translation
activities
- Pedagogical role of
translation
- Integration of translation
activities to courses
- Mediation role of the
learner
- Learner as a Social Actor
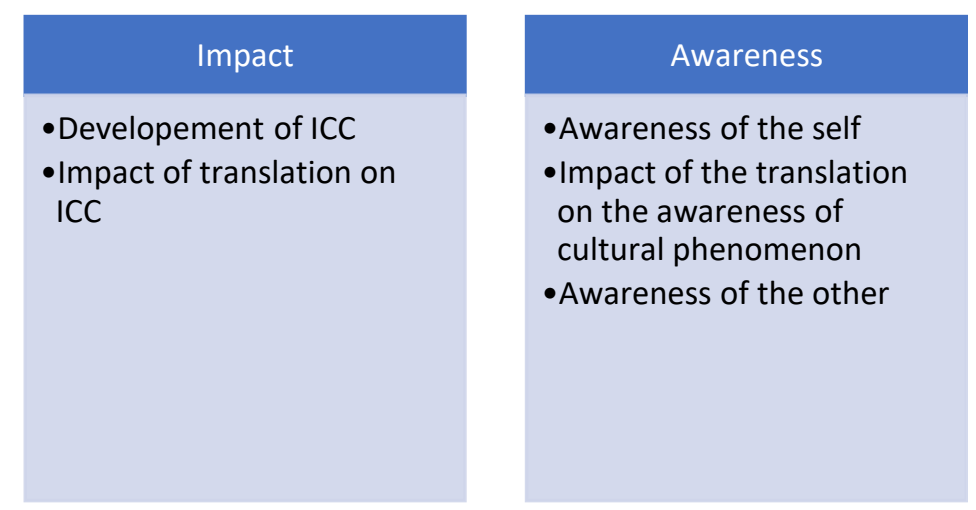

\section{FINDINGS}

Responses obtained in the interviews were analysed under three themes, these themes are the role of translation activities in courses, the impact of translation on ICC development and the intercultural awareness of the learner.

\section{The Role of Translation Activities}

\section{Table 3. The Role of Translation Activities}

\section{ROLE OF TRANSLATION ACTIVITIES}

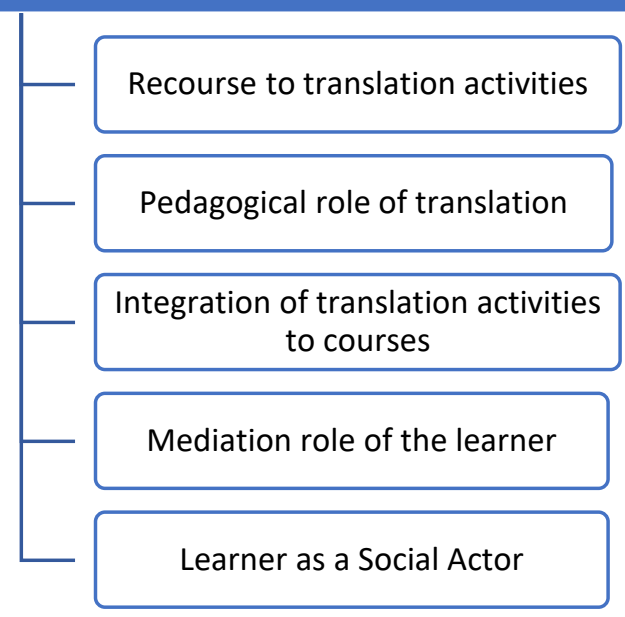

\section{Recourse to the translation activities}

Most of the participants (8/10) stated that they have recourse to the translation activities during their courses. $\mathrm{P}(8)$ and $\mathrm{P}(4)$ stated that they never have recourse to translation activities during their courses, $\mathrm{P}$ (3) revealed that once they started to use translation the students have tendency to use the L1. P (4) declared that she does not affirm the usage of translation, because it affects the usage of the language negatively.

Recourse to translation activities has been a controversial issue among language teachers due to their various conceptions on the issue which stem from a historical rupture between various conceptualisation of the usage of translation activities in FLT. In FLT, the role granted to translation has been divergent. During Grammar-Translation method it was the main activity at the centre of 
language learning, but with the emergence of methods focusing on the development of verbal skills it was started to be neglected, then rehabilitated as a pedagogical tool in language learning in last decades (Cook 2010; Leonardi, 2010; Malmkjaer, 1998; Kocbek 2013). But on the other hand, Cook (2009) defines the detrimental effect of translation on L2 acquisition which was heavily influenced by L1.

\section{The pedagogical role of translation}

Learners mostly have recourse to translation activities especially in order to elucidate the meaning, to ease understanding between structures, to ease understanding of complicated situations and phrases, to elucidate the connotations and denotations of various cultural codes, to motivate the learners and to control the understanding of students. Some participants state that a word to word translation in courses influence the learner negatively and the usage of L2 becomes difficult and decelerated. Instead it is better to orient learners to find equivalences of the words both on a cultural and linguistic level. One of the participants stated the pedagogical role of translation as follows:

P (3) stated that she utilizes translation activities to facilitate the access to the meaning of the difficult worlds, the scientific terms, the written passages of the students to resume the case. These activities are made orally, in a rapid way and especially in the theoretical courses as linguistics, the phonetic system of French and the didactic of French as a second language. For her, the translation could be used as a mean of control of the comprehension in the practical courses of foreign language teaching, but limitedly. These activities could be used in the moments of explication or exploitation of the course just like a natural activity of translation. They should be applied orally which could consequently move the student away from the mechanism of word-to-word translation and orient $\mathrm{him} / \mathrm{her}$ to the reformulation activities. Lado (1964) states that the use of translation in the language classroom encourages a word-for-word rendering between the L1 and the L2.

P7 uses translation for controlling purposes to resume the subject. As she declared, it is required to study with texts, to develop interpretative competence, and to assist students to find especially the inedited equivalences. Therefore, the translation could become an instrument of perfection.

\section{Integration of translation activities to courses}

Two of the participants (P8 and P4) never integrate translation activities to their courses.

P7 integrates it only for resuming purposes and she states that she never allows students to translate because they have tendency to translate word-to-word. P9 integrates it according to the context when she thinks it is required. Her purpose "is to demonstrate the social usage of the word and to make students understand the context totally and to prevent the misunderstandings during the communication situations when encountered with a native speaker." P5 integrates the translation in a comparative approach between L1 and L2. P6 integrates translation in order to facilitate the understanding and to make the students participate actively to the course. It is because some interpretations in German become insufficient for certain students who ask for a feedback in Turkish."

P3 gives theorical courses, she does not aim the teaching of the foreign language necessarily but the relevant knowledge of the field studied. As a result, she integrates easily the translation to her courses in order to facilitate the transmission of the message and in the cases when she recognises a difficulty of the comprehension. 
P1finds translation activities useful in teaching grammar, especially to differentiate between structures. P2 uses the translation to explain a grammatical rule in order to make students understand completely. As it is stated by the participants, translation activities mostly integrated to make the students to grasp the meaning completely, to facilitate grammar teaching or to transmit the message correctly for the courses which necessitates a much more understanding of the language in question due to the loaded knowledge in the courses like linguistics, acquisition of language etc. Translation has recently witnessed a revival in the field of language analysis (Gotti and Sarcevic, 2006). It is required to make students react correctly in a social context. Cook (2013) points to a growing literature which supports a return to bilingual teaching for a number of acquisitional, pedagogic, political and educational reasons.

\section{Mediation role of the learner via translation}

P5 In the classroom, the teacher can propose similar activities to daily life. Even though the class is limited to realise them, the Internet offer many possibilities to surpass such limits. And the learner as a mediator between two cultures can share the results of his/her researches and discoveries with the partners who do not know the L2. P6 states that once the learner starts to learn the language, she/he automatically becomes a mediator.

P2: Via the usage of a forum or blog on the Internet the learner could share his/her view with the target language interlocutors and gives information about his/her own culture as a mediator. P7: At first glance, we should fix some objectives, which are real and realisable. For example, when we ask the learner to make reportage, he/she should have the questions to ask and the necessary materials. In addition, their effort should be appreciated. They should be able to work with the students of the target language country. Therefore, they can share their experiences and results. In that way, they can be real mediators. With the recent technology, it is possible to fix communicative objectives.

As it is stated above, the participants unanimously affirm the importance of the mediation role of the translation between two languages and cultures. Even though it seems as a difficult objective to achieve, they claim that with the expansion of the usage of internet the learners turned more and more to be a mediator as a language learner between two countries and cultures. This is said, translation becomes an activity expanded worldwide and Richards and Rogers (1999) states that translation has never been completely abandoned.

\section{Learner as a social actor via translation}

P4 states that the learners should become social actor between two languages in order to develop the tolerance, empathy and communication with the target culture interlocutors".

P9: The target language should be taught by a focus on the social usages (if the context and the in-class structures and interactions allow to). The intercultural communicative competence is so crucial in order to establish a correct understanding and expression in the society in which the target language is used via verbal and non-verbal elements. The learner should choose the appropriate elements to communicate in order to ensure a serein understanding. Therefore, as the intercultural communicative competence development directly influences the pragmatic usage of the language, I do not believe in the possibility of development of the usage of translation activities in classroom in order to enhance the intercultural communicative competence. 
Participants affirm that learning a different language appeals empathy and tolerance for people having different life stories. As a language learner, a person develops his/her sense of empathy, which in turn leads to raise awareness towards global social issues and social problems/ misunderstandings with a higher sense of responsibility.

P3: The most important part of the course is dedicated to the acquisition of a content of sociolinguistic. If the learner is incited to participate actively to interactions in class, and to document his/her researches and if we put the learner in an authentic lingual context, varied and interesting, there will be more chance to see the learner more implicated in the course. In fact, to feel more capable of manipulating a new language should be the best mean to approach the other's culture without prejudice, neither hesitation and with more interest.

P6: It is crucial to make the learner understand that it is possible to think in foreign language without preventing him/her of thinking in L1. To ensure the transfer in both languages... The learner could become a social actor by having a competence to transfer the language mentally in both languages.

P8: The learner could be a social actor thanks to autonomy. They use autonomy for teaching purposes. The learner should acquire a competence to learn in autonomy and the realisation of projects render the learner a social actor, because they have the tasks to realise in order to achieve a certain objective.

As participants state above, the learners become a social actor and play the role of a mediator between two languages and cultures via translation. They develop easily a sense of tolerance, empathy and approach the other's culture without prejudice, neither hesitation and mostly with more interest, thus she/he becomes more attentive against the misunderstandings with a higher sense of responsibility.

\section{The Impact of Translation Activities to Develop ICC}

\section{Table 4 The Impact of Translation Activities to Develop ICC}

$$
\begin{aligned}
& \text { IMPACT OF TRANSLATION } \\
& \text { ACTIVITIES } \\
& \qquad \begin{array}{c}
\text { Impact of the } \\
\text { Development of ICC } \\
\text { translation on ICC }
\end{array}
\end{aligned}
$$

\section{Development of ICC}

P8 prepares a course about the French culture once per week. (Especially clichés feast etc.) We do comparison of two cultures. P10 tries to explain the occurrence of the translation, literature, musical, pictorial, photographical activities from daily life in the target language and foreign one to develop ICC. P5 creates occasions in order to make them understand the target culture by discovering the cultural events, by developing their personal experiences and vision on the target culture. P2 uses films, songs and journals in order to develop intercultural communicative competence. 
Teachers are mostly aware of the cultural boundaries in language learning and they act in a way to make the students surpass these boundaries via integrating the ICC in their courses. In doing this, they awake certain curiosity on the foreign language and culture and evoke the cultural aspects of the target language.

\section{Impact of the translation on ICC}

P9 thinks that translation does not have positive effects on the development of intercultural communicative competence due to the fact that it orients the learner to think in L1 and to transfer it in L2 and force him/her to think in L1."

P7 states that usage of authentic texts permits to discover the vision of the other culture, which makes it possible to be tolerant against the differences. It contributes to the personal development. According to P2, the usage of L1 in courses enhances the feeling of belonging to one's culture. P8 stated that she never uses translation activities just as P6 who never uses translation activities during the courses.

Most of the teachers stated that the usage of L1 in courses was neglected via the problems of transference and interference between two languages, but when it is neglected, it leads learners to the lack of intercultural competent and to the sublimation of the culture of the target language whereas the intercultural competence is to accept the culture of the other and to know his/her own culture. It is evident that as we see the L1 as a porter or part of the culture, we could not neglect L1 usage. It is acceptable therefore to use $\mathrm{L} 1$ or translation without an excessive recourse.

\section{Awareness Raising Via Translation Activities}

Table 5. Awareness Raising Via Translation Activities

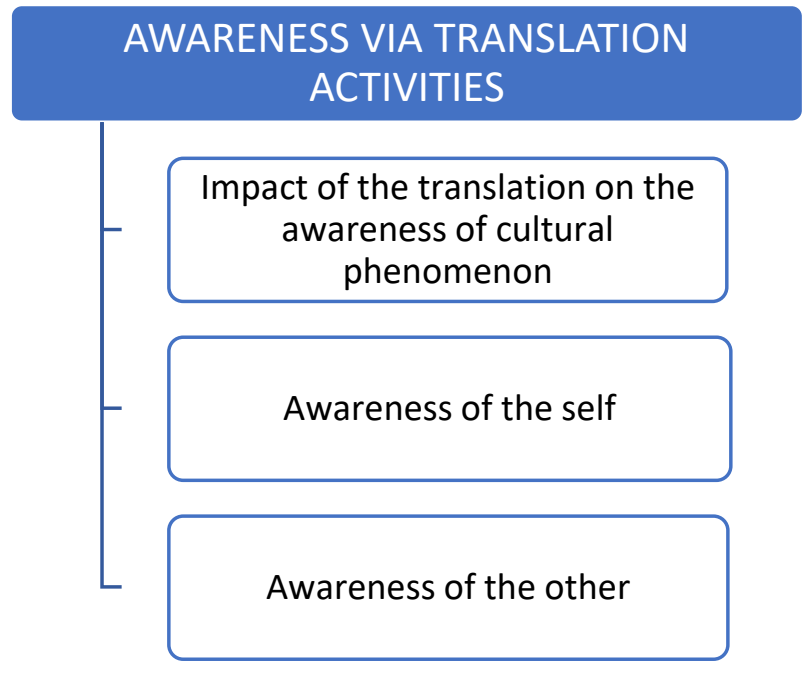

\section{Impact of the translation on the awareness of cultural phenomenon}

P6 declared that she tries to transfer the names, places, way of life, nutrition habitudes, feast etc. in the target culture. P1 mainly uses the main course books that raise such issues; and related activities include, reading on differences between cultures, watching videos about cities and the lifestyle of people in the target culture, and discussing about these differences and similarities between the target 
culture and that of the learners. According to her idioms also work well with the issue, so, the learners improve their understanding of the way the people of the target culture think and behave in specific situations.

P10 thinks that the learner would be able to communicate competently enough without translation activities when he/she finds the possibility to express himself/herself fluently without being shy or afraid in foreign language as a learner who perceive correctly the way of life, culture and logic of the target culture. Therefore, she believes in the importance of translation activities between the learner and teacher until the prejudices and the feeling of failure had been broke down.

P3 declares that the recourse to translation attract the attention of the learner to the relation between language and culture, she thinks that the lingual expressions as vehicle of culture serve to break down the ethnocentrism.

Teachers stated that the recourse to the translation activities and the lingual expressions as vehicle of culture serve to break down the ethnocentrism which leads the learner to appreciate not only his/her own culture and language but also the other's. The awareness in both languages help him/her to face some stereotypes and prejudices. They surpass not only the dichotomy of language/culture but also self/other.

\section{CONCLUSION AND DISCUSSION}

Language learning is a way of building a bridge between his/her own culture and that of the target culture. In that sense, it would not be considered as a set of rules transferred to the learner but also the culture is conveyed via the language in question. Culture is the principal aspect of the language, which leads the learner to cope with not only linguistic competence but also social and pragmatic usage of it. It is an asset to be familiarized with the cultural and social dimensions of any language in a language-teaching classroom. Mostly, teachers shortcut this dimension due to its difficulties, problematic issues turning around the requirement to face some stereotypes and prejudices and lack of their own background respectively.

As Nord (1997, p.1) asserts "communication takes place through a medium and in situations that are limited in time and place. Situations are not universal but embedded in a cultural habitat, which in return conditions the situation. Language is thus to be regarded as a part of culture and communication is conditioned by the constraints of the situation in culture." According to Tudor, "translation can be interpreted in two ways: as a text production process dependent upon proficiency in all four skills whose final goal is a refined linguistic competence or as a communicative activity whose objective is to convey messages across linguistic and cultural barriers" (1987, p. 269). The close connection between language and culture implies intercultural awareness, which is indispensable to perfect communicative competence. (Fois, 2020, p. 564) So, translation is a way to surpass cultural boundaries and the role of translating is a kind of mediation and it is crucial as a learner to have a communicative, cultural competence in order to understand not only the language but also the culture of the other to adapt, to transpose and to explain beyond the mere words. The translation is not only an activity of transcoding, but also a complex procedure in which interfere the language, the culture, but also the inter-subjective relations between individuals and the society. Besides, the non-verbal communication is generally unconscious and indeed essential part of the communication and interpretation activity. The behaviour of individuals, which is perceptible, is a way that leads to the understanding of the world and the hierarchical values of the other which remains mostly invisible of 
the cultural aspect. These are decoded mostly in accordance with the culture and language. However, this diversity of the values in a social and cultural level is an important source of misunderstandings in the teaching-learning process of a foreign language. In addition, translation is the key factor to prevent these misinterpretations in a multicultural and multilingual environment.

Pedagogical translation could not be only seen as a way, which leads to the other cultures or languages, moreover it is a gate opened to the awareness of the culture of the self. As the one is not separated from the other and the language is the key factor to warrantee this union, on its turn the language could not be achieved without translation activities, which plays mostly the role of a mediator between two counterparts. The teachers in the classroom and translation activities fulfil this mediation. It is crucial to be aware of the target language and native language at the same time, so the translation in the classroom replaces sometimes the teacher as a mental cognitive action, because in each act of language the learner as a lecture or writer applies to the translation cognitively. As a result, he/she encounters not only the linguistic but also pragmatic use of the target and native language simultaneously. This act enhances his/her ability or awareness irreversibly in both languages and cultures. His/her intercultural and inter-lingual abilities develop according to his/ability and manoeuvres in both languages which is a positive asset in language/culture dichotomy.

Translation is the mere act to deconstruct the dichotomy mentioned above between language and culture. Noticeable trends include a continued interest in deconstructing cultural differences and membership through interculturality studies in which scholars seek to interpret how participants make aspects of their identities, in particular, socio-cultural identities relevant or irrelevant to interactions through symbolic resources including, but not solely, language (Kramsch, C., \& Zhu Hua, 2016, p.48). This deconstruction is based upon the development of an Intercultural Communicative Competence among learners by putting them in a face-to-face interaction with not only the text in the foreign language but also the verbal aspect of it. The deconstruction in question ensures the appropriation of both language and the culture for the learner. For Leonardi, translation is a productive activity that focuses on contextualization and recontextualization. (2010, p.20) While translating a text, whether orally or in a written format, the learner activates his/her linguistic competence in a way to be in contact functionally with the context of the target language and culture. Therefore, he/she becomes a social actor and mediator in between two languages/cultures. Doing this, the learner faces both the linguistic structure and pragmatic elements and usages of the native and the target language and gets an insight in both of them. Translation becomes the bridge between them for the learner who becomes acquainted with the target culture via linguistic structures, catches the implications and do inferences on the pragmatic usage in L1 and L2, which enriches his/her grasp of the language /culture aspects in spoken and written forms. These implications, inferences and inductions contribute mostly the development of Intercultural Communicative Competence, which requires an inter-cultural and interlingual acquisition depending on the capacity, knowledge and expertise of the learners in both languages. This expertise easily acquired through translation activities in and outside the class influences the fluency of the communication and prevents in most cases the misunderstandings directly. So, the learner not only appeal to the cultural referents and also linguistic structures which orients the learner to the development of an inner-sight by breaking down stereotypes, prejudices visà-vis the target culture and social phenomenon.

For further studies, the researcher suggests:

- Examination of the role of social actor for the learner via translation activities

- Examination of the language teacher as a cultural mediator between two languages 
- The impact of translation activities to the awareness of the self and the other culture

- To develop the interaction among learners via translation and culture contact

- Enhance cultural motivation of learners to approach the culture of the other via translation

- To decrease the misunderstandings via translation and transfer process of cultural baggage.

- The usage of translation as a learning strategy to access the culture of the other and the self.

The insight developed by referring to the translation ensures respectively a sound and lucid communication between the learner and the practitioners of a wide range in the target language, which is an important aim in the case of English-spoken world for instance which is spread out in the world. It is a mean to overcome misunderstandings and misinterpretations not only in the linguistic, communicative, but also pragmatic level.

\section{REFERENCES}

Anderson, L. (2018). Fostering metalinguistic awareness: Role play, pragmatics and L2 literary translation. In L.Anderson ,L.Gavioli, \&F.Zanettin (Eds.), Translation and interpreting for language learners . [Special Issue]. inTRAlinea.

Beaven, T. \& Álvarez, I. (2004). Translation Skills for Intercultural Purposes: An On-line Course for Non-specialist Learners of Spanish, 17:2, 97-108

Beneke, J. (2000). Intercultural Competence. In: U. Bliesener (Ed.) Training the trainers, International Business Communication, vol.5, Carl Duisberg Verlag) pp. 108-109)

Byram, M. (2000). Assessing intercultural competence in language teaching. Sprogforum 18 (6), 8-13.

Byram, M.\& Zarrate. G. (1996). Defining and assessing intercultural competence: some principles and proposals for the European context, Language Teaching, Volume: 29, Issue: 4, October, pp. 239-243

Byram. M.\& Fleming, M. (1998). Language learning in intercultural perspective: Approaches through drama and ethnography. Cambridge: Cambridge University Press.

Byram, M., Nichols, A.\& Stevens, D. (2001). Developing Intercultural Competence in Practice, Multilingual Matters

Byram, M., Gribkova, B., \& Starkey, H. (2002). Developing the intercultural dimension in language teaching: A practical introduction for teachers. Strasbourg: Council of Europe. Higher Education, Council of Europe: Strasbourg, France

Byram, M., Holmes, P., \& Savvides, N. (2013). Guest Editorial. Intercultural communicative competence in foreign language education: questions of theory, practice and research. The Language Learning Journal, 41(3), 251-253

Canale, M. \& Swain M. (1980). Theoretical Bases of Communicative Approaches to Second Language Teaching and Testing. Applied Linguistics, 1,1-47.

Cook, G. (2010) Translation in Language Teaching: An Argument for Reassessment, Oxford: Oxford University Press

Cook, G. (2013). Translation in language teaching. In M. Byram, \& A. Hu (Eds.), Routledge encyclopedia of language teaching and learning (2nd ed., pp. 737-740). New York/London: Routledge.

Davies, Eirlys E. (2012). Translation and Intercultural Communication. Bridges and Barriers in Christina Bratt Paulston, Scott of Kiesling \& Elizabeth Rangel (eds.) The Handbook of Intercultural Discourse and Communication, 367-388 Chichester, West Sussex: Willey Blackwell,

Elorza, I. (2008). Promoting Intercultural Competence in the FL/SL Classroom: Translations as Sources of Data Language and Intercultural Communication 8(4): 261-277. 
Fanon, F. (1967). Black Skin, White Masks, Trans. Charles Lam Markmann, New York: Grove Press, Inc.

Fois, E. (2020) ELT and the role of translation in developing intercultural competence, Language and Intercultural Communication, 20: 6, 561-571

Gotti, M. \&Sarcevic, S. (2006). Insights into Specialized Translation (Linguistic Insights), Peter Lang

Krieger H., Lazar M. I. \& Strange J. (2003) Mirrors and Windows. An Intercultural Communication Textbook. Granz: European Centre for Modern Languages/Council of Europe.

Hymes, D.H. (1972) "On Communicative Competence" In: J.B. Pride and J. Holmes (eds) Sociolinguistics. Selected Readings. Harmondsworth: Penguin, pp. 269-293.

Kocbek A. (2014). Unlocking the potential of translation for FLT. Linguistica, 54(1), 425-438

Kramsch, C. (1998). Language and Culture, Oxford: Oxford University Press.

Kramsch, C. J. (2013). Afterword. In B. Norton, Identity and language learning: Extending the conversation (2nd ed., pp. 192-201). Bristol, UK: Multilingual Matters.

Kramsch, C., \& Zhu Hua (2016). Language, Culture and Language Teaching. In G. Hall (Ed.), Routledge Handbook of English Language Teaching (pp.38-50). London: Routlege

Lado, R. (1964). Language teaching: A scientific approach. New York/San Francisco/ Toronto/ London: McGraw-Hill.

Leonardi, V. (2010). The Role of Pedagogical Translation in Second Language Acquisition, From Theory to Practice, Peter Lang

Malmkjaer, K. (1998). Translation and Language Teaching: Language Teaching and Translation, Macnhester: St. Jerome Publishing.

Marton, F. (1986, Fall). Phenonemography- A Reseach Approach to Investigating Different Understandings of Reality, Journal of Thought, 21, 3, pp. 28-48

Meyer, Lois M. (1991). The Language Circle: Inside the Teaching and Learning of Language in an Inner-City Elementary School, Los Angeles: University of California.

Miles, Mathew B., Huberman, Micheal A., Saldana, Johnny, (2014). Qualitative Data Analysis A Methods Sourcebook, Los Angeles: Sage Publications

Naimushin, B. (2002). Translation in Foreign Language Teaching: The Fifth Skill. Modern English Teacher, 11 (4). pp. 46-49

Nord, C. (1997). Translating as a purposeful activity, functionalist approaches explained, Manchester: St. Jerome Press.

Richards, J. C. \& Rogers. T. S. (1999). Approaches and Methods in Language Teaching, Cambridge University Press

Tight, M. (2016). Phenomenography: the development and application of an innovative research design in higher education research, International Journal of Social Research Methodology, 19:3, 319-338

Tudor, I. (1987). Using Translation in ESP, ELT Journal, 41(4), 268-273

Vermes, A. (2010). Translation in Foreign Language Teaching: A Brief Overview of Pros and Cons, Eger Journal of English Studies, 10, 83-93.

Woo Lee, M. (2018). Translation revisited for low-proficiency EFL writers. ELT Journal,72 (4), 365373.

Yates, C., Partridge, H. L., \& Bruce, C. S. (2012) Exploring information experiences through phenomenography. Library and Information Research, 36(112), pp. 96-119. 


\section{APPENDIX}

Interview questions are defined as below:

1. Do you have recourse to translation activities for didactic purposes during your courses? Especially in which courses, situations and contexts?

2. How do you perceive the didactic role of translation in foreign language teaching?

3. How do you integrate the translation to your courses? What is your main purpose in this integration process of translation to the foreign language teaching?

4. What kind of activities do you use to develop an insight in the learners both to enhance the awareness of the culture of the self and the others?

5. How do you contribute to the development of intercultural Communicative Competence during your courses?

6. What is the impact of the pedagogical translation to the development of Intercultural Communicative Competence according to your professional experiences in class?

7. Based upon your experiences, what is the way to make learners a social actor in language learning process and mediator in between two cultures, as it is required in Common European Framework of Reference for Languages?

Interview consent form is designed as below:

Interview consent form and open-ended questions for the survey entitled "The Influence of Pedagogical Translation in the Development of Intercultural Communicative Competence in Language Teaching- A phenomenological survey on the perception of language teaching professionals" conducted via E-Mail.

The questions below are open-ended questions, prepared by the researcher in order to study the impact of pedagogical translation in the development of Intercultural Communicative Competence in Foreign Language Teaching classrooms. (The study does not include the translation courses, but it is rather about the usage of translation in language teaching classes). The data will remain confidential and your responses will be used in academic purposes for a qualitative survey. In the final paper your names will not be mentioned, instead numeric or alphabetic pseudonyms will be used.

Age:

Department:

Title:

University:

Teaching Experience: 